\title{
Hubungan Faktor Individu dan Faktor Pekerjaan terhadap Keluhan Musculoskeletal Disorders pada Pegawai
}

\section{Relationship of Individual and Occupational Factors to Complaints of Musculoskeletal Disorders among Employees}

\author{
Putri Tika Rahayu1, Marina Ery Setiyawati ${ }^{2}$, Cahya Arbitera ${ }^{3}$, Afif Amir Amrullah ${ }^{4}$ \\ Fakultas Ilmu Kesehatan, Universitas Pembangunan Nasional Veteran Jakarta, Indonesia
}

\section{ARTICLE INFO}

\section{Article history}

Received date

01 Oct 2020

Revised date

20 Oct 2020

Accepted date

12 Nov 2020

Keywords:

Employees;

Musculoskeletal

disorders;

Work posture.

Kata kunci:

Pegawai; Musculoskeletal

disorders;

Postur kerja.

\begin{abstract}
ABSTRAK
Musculoskeletal disorders are work-related diseases and conditions that are not safe and uncomfortable, almost all employees have experienced the disorders, ranging from pain in the neck, shoulders, and lower back. This study was conducted to determine the relationship of individual factors and work factors to complaints of musculoskeletal disorders in employees at the Ministry of Health's Republic of Indonesia Civil Service Bureau in 2020. This study used a cross-sectional study design with the Purposive Sampling technique, with a sample of 103 employees. The research instruments used in the study were the questionnaire regarding individual characteristics, Rapid Office Strain Assessment (ROSA), Nordic Body Map (NBP), and Global Physical Activity Questionnaire (GPAQ) questionnaire. The result of this study indicates that the variables related to complaints of musculoskeletal disorders are age ( $\mathrm{p}$-value $=0,001)$, work period ( $p$-value $=0,001)$, and work posture ( $p$-value $=0,001)$, while gender, BMI, physical activity, duration of the word are not related to complaints of musculoskeletal disorders. Employees must do physical activity 3 times a week, need to reorganize the design of the workplace so it can reduce the presence of awkward posture, and pay more attention to the position of the body at work.
\end{abstract}

\begin{abstract}
Musculoskeletal disorders merupakan penyakit yang berhubungan dengan pekerjaan dan keadaan yang tidak aman dan kurang nyaman, hampir semua pegawai pernah mengalami gangguan tersebut, mulai dari nyeri pada bagian leher, bahu, dan punggung bawah. Penelitian ini dilakukan untuk mengetahui hubungan faktor individu dan faktor pekerjaan terhadap keluhan musculoskeletal disorders pada pegawai di Biro Kepegawaian Kemenkes RI tahun 2020. Penelitian ini menggunakan desain penelitian studi Cross Sectional dengan teknik Purposive Sampling, jumlah sampel yaitu 103 pegawai. Instrumen penelitian yang digunakan dalam penelitian ini adalah kuesioner mengenai karakteristik individu, Rapid Office Strain Assessment (ROSA), kuesioner Nordic Body Map (NBM), dan kuesioner Global Physical Activity Questionnaire (GPAQ). Hasil penelitian ini menunjukkan bahwa terdapat variabel yang berhubungan dengan keluhan musculoskeletal disorders adalah usia $(p$-value $=0,001)$, masa kerja $(p$-value $=0,001)$, dan postur kerja ( $p$-value $=0,001)$, sedangkan jenis kelamin, IMT, aktivitas fisik, dan durasi kerja tidak memiliki hubungan dengan keluhan musculoskeletal disorders. Sebaiknya pegawai melakukan aktivitas fisik sebanyak 3 kali seminggu, perlu menata ulang kembali desain tempat kerja sehingga dapat mengurangi adanya postur janggal, dan lebih memperhatikan posisi tubuh saat bekerja.
\end{abstract}

Corresponding Author:

Putri Tika Rahayu

Fakultas Ilmu Kesehatan, Universitas Pembangunan Nasional Veteran Jakarta, Indonesia

Email: putritikarahayu@upnvj.ac.id

\section{PENDAHULUAN}

Musculoskeletal disorders (MSDs) pada umumnya dilaporkan oleh pekerja kantor di seluruh dunia, gangguan ini memiliki efek yang dapat merugikan pada kesehatan dan produktivitas pekerja. Faktor-faktor risiko berkembang sehingga terjadinya MSDs dapat 
dibagi menjadi faktor individu, faktor ergonomis, dan faktor psikososial (Mahmud, et al., 2011). Istilah gangguan musculoskeletal menunjukkan masalah kesehatan yang terjadi pada alat-alat gerak tubuh seperti, otot, tendon, kerangka tubuh, tulang rawan, ligamen, dan saraf. Keluhan pada sistem musculoskeletal merupakan keluhan yang terdapat dari bagian otot rangka yang dirasakan seseorang berawal keluhan sangat ringan hingga sangat berat. Dari keluhan hingga datangnya kerusakan inilah yang biasa dikatakan sebagai MSDs atau cedera dalam struktur musculoskeletal (Krisdianto dkk, 2015).

Kebanyakan gejala yang muncul tidak diperhatikan, karena mereka menganggap bahwa hal tersebut sudah biasa, sebenarnya kelelahan merupakan awal dari munculnya penyakit akibat kerja (Aziz, dkk, 2018). Pekerja kantor merupakan pekerjaan yang memiliki prevalensi gangguan musculoskeletal yang tinggi. Beberapa penyebab gangguan MSDs seperti duduk yang lama, bekerja menggunakan komputer, pekerjaan berulang, postur kerja statis, dan kondisi lingkungan yang buruk. Penyebab gangguan musculoskeletal disorders terjadi pada bagian tangan, leher, lengan, pundak, dan pergelangan tangan pada pekerja kantor (Valipour Noroozi , et al., 2015).

Berdasarkan berita dari International Labour Organization (2017) sebanyak 860.000 tenaga kerja di seluruh dunia mendapati kecelakaan dan penyakit akibat kerja setiap harinya (Dewi, 2019). The prevention of Occupational Diseases menginformasikan bahwa MSDs memiliki prevalensi 59\% dari keseluruhan catatn penyakit yang ditemukan di Eropa (WHO, 2013). Menurut data yang diperoleh dari Labour Force Survey (LFS) di UK, membuktikan MSDs terjadi pada pekerja sangat tinggi yakni sejumlah 1.144.000 kasus dengan distribusi kasus yang menyerang punggung sebesar 493.000 kasuss, anggota tubuh bagian atas atau leher 426.000 kasus, dan anggota tubuh bagian bawah 224.000 kasus. Hasil penelitian sejenis yang dilakukan di Amerika terdapat sekitar 6 juta kasus MSDs pertahun atau rata-rata 300-400 kasus per100.000 orang pekerja (Sekaaram dan Ani, 2017)

Di Malaysia kasus MSD yang dilaporkan dari the Social Security Organization (SOCSO) telah meningkat pesat sejak tahun 2005 dari 10 kejadian menjadi pada tahun 2014 naik 675 kejadian (Luan, et al., 2018). Berdasarkan hasil riset kesehatan dasar presentase MSDs sebesar $11,9 \%$ yang diperiksa oleh nakes di Indonesia dan hasil pemeriksaan atau tanda-tanda sebanyak 24,7\% (Badan Penelitian dan Pengembangan Kesehatan, 2013).
Banyak penelitian melaporkan terdapat hubungan yang signifikan antara musculoskeletal dan faktor risiko individu (usia, jenis kelamin, IMT, dan merokok) (Piranveyseh, et al., 2016). Hal ini menandakan bahwa terdapat hubungan yang bermakna antara postur kerja dengan keluhan MSDs pada pegawai administrasi di Kantor Pusat Universitas Jember (Dewi, 2019).

Berdasarkan hasil studi pendahuluan yang dilakukan peneliti dengan pengamatan serta wawancara terhadap pegawai di Biro Kepegawaian Kemenkes RI yang dilakukan pada tanggal 1 Maret 2020 terdapat 18 pegawai dari 20 pegawai yang mengalami keluhan musculoskeletal disorders karena bekerja dengan sikap duduk yang tidak alamiah karena desain kursi yang tidak ergonomi dengan waktu duduk cukup lama di depan komputer atau laptop, kebanyakan keluhan yang terjadi seperti nyeri pada bagian leher, bahu, punggung bawah, dan bagian lainnya pada saat bekerja di Biro Kepegawaian Kemenkes RI. Melihat persoalan yang ada, peneliti merasa perlu untuk melakukan penelitian dengan judul "Hubungan Faktor Pekerjaan dan Faktor Individu Terhadap Keluhan Musculoskeletal Disorders pada Pegawai di Biro Kepegawaian Kementerian Kesehatan Republik Indonesia Tahun 2020".

\section{METODE}

Penelitian ini dilakukan untuk mengetahui hubungan faktor pekerjaan dan faktor individu terhadap keluhan musculoskeletal ldisorders pada pegawai di Biro Kepegawaian Kementerian Kesehatan Republik Indonesia Tahun 2020 yang dilihat dari faktor individu (jenis kelamin, aktivitas fisik, durasi kerja, Indeks Massa Tubuh (IMT),dan usia) dan faktor pekerjaan faktor pekerjaan (postur kerja dan durasi kerja). Penelitian ini dilakukan di Direktorat Kesehatan Kerja dan Olahraga, Kementerian Kesehatan yang bertempat di Gd. Dr. M. Adhyatma, MPH Lantai 07 No. 722Jl. H.R. Rasuda Said Blok X-5 Kav.4-9 Jakarta Selatan 1295.

Penelitian ini merupakan penelitian kuantitatif dengan desain penelitian cross sectional, teknik yang digunakan pada penelitian ini purposive sampling dengan jumlah sampel yang digunakan 103 dan dilakukan pada bulan Maret-Juli 2020. Dalam penelitian ini pengambilan data dilakukan dengan pengisian lembar kerja penilaian Rapid Office Strain Assessment (ROSA) untuk melihat tingkat risiko postur kerja, kuesioner Nordic Body Map (NBM) guna melihat jumlah orang yang dengan keluhan 
musculoskeletal, kuesioner Global Physical Activity Questionnaire (GPAQ) untuk menghitung tingkat aktivitas fisik dari faktor pekerjaan dan faktor individu, dan kuesioner tentang karakteristik individu yang diisi oleh pegawai di Biro Kepegawaian Kementerian Kesehatan Republik Indonesia.

Populasi dalam penelitian ini adalah seluruh pegawai di Biro Kepegawaian Kemenkes RI sebanyak 122 pegawai pada bulan Maret 2020. Pengambilan sampel pada penelitian ini ditentukan dengan mengunakan rumus Slovin. total sampel akhir penelitian ini adalah 103 responden di Biro Kepegawaian Kementerian Kesehatan RI. Pada penelitian ini data dianalisis menggunakan analisis univariate untuk distribusi frekuensi dan analisis bivariate untuk mengetahui hubungan antara dua variabel dengan menggunakan uji chi-square.

Penelitian ini telah mendapatkan Persetujuan Etik (Ethical Approval) dengan Nomor: B/2524/VI/2020/KEPK oleh Komisi Etik Penelitian Kesehatan Universitas Pembangunan Nasional Veteran Jakarta.

\section{HASIL}

Tabel 1. Distribusi Frekuensi Keluhan Musculoskeletal Disorders pada Pegawai

\begin{tabular}{lrr}
\hline \multicolumn{1}{c}{ Keluhan } \\
Musculokeletakal & Jumlah & \multicolumn{1}{c}{$\%$} \\
\hline Sedang & 49 & 47,6 \\
Rendah & 54 & 52,4 \\
Total & 103 & 100,0 \\
\hline
\end{tabular}

Berdasarkan tabel 1, dapat diketahui bahwa sebagian besar pegawai di Biro Kepegawaian Kementerian Kesehatan RI mengalami keluhan rendah musculoskeletal dengan 54 pegawai atau $(52,4 \%)$ dari 103 responden.
Tabel 2. Distribusi Frekuensi Faktor Individu pada Pegawai

\begin{tabular}{lrr}
\hline \multicolumn{1}{c}{ Variabel } & Jumlah & \% \\
\hline Usia & & \\
$>37$ Tahun & 53 & 51,5 \\
$\leq 37$ Tahun & 50 & 48,5 \\
Jenis Kelamin & & \\
$\quad$ Laki-laki & 51 & 49,5 \\
$\quad$ Perempuan & 52 & 50,5 \\
IMT & & \\
$\quad$ Gemuk & 45 & 43,7 \\
$\quad$ Kurus & 2 & 1,9 \\
$\quad$ Normal & 56 & 54,4 \\
Aktifitas Fisik & & \\
Aktifitas Fisik & 46 & 44,7 \\
Kurang & & \\
$\quad$ Aktifitas Fisik & 57 & 55,3 \\
Cukup & & \\
Masa Kerja & & \\
$\quad>10$ Tahun & 74 & 71,8 \\
$\leq 10$ Tahun & 29 & 28,2 \\
\hline
\end{tabular}

Terlihat dari tabel 2, menunjukkan bahwa pegawai di Biro Kepegawaian Kemenkes sebagian besar memiliki usia > 37 tahun yaitu sebanyak 53 pegawai atau $(51,5 \%)$ dari 103 responden. Jenis kelamin pegawai di Biro Kepegawaian Kemenkes RI yaitu perempuan sebanyak 52 atau $(50,5 \%)$ dari 103 responden. Pada variabel indeks masa tubuh sebagian besar pegawai di Biro Kepegawaian dengan IMT normal sebanyak 56 pegawai atau $(54,4 \%)$ dari 103 responden. Terdapat sebanyak 57 pegawai atau $(55,3 \%)$ dari 103 responden memiliki aktivitas fisik cukup. Dari 103 responden, sebanyak 74 pegawai di Biro Kepegawaian atau $(71,8 \%)$ memiliki masa kerja $>10$ tahun.

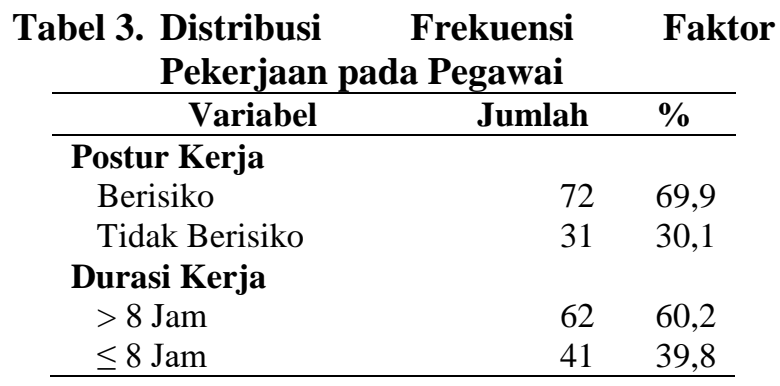

Berdasarkan tabel 3, dapat diketahui bahwa mayoritas dari 43 pegawai di Biro Kepegawaian atau $(59,7 \%)$ dengan postur kerja bersiko mengalami keluhan tinggi musculoskeletal disorders. Pada pegawai di Biro Kepegawaian dengan durasi kerja $>8$ jam sebanyak 35 pegawai atau $(56,5 \%)$ mempunyai keluhan tinggi musculoskeletal disorders. 
Tabel 4. Analisis Bivariat antara Faktor Individu dengan Keluhan Musculoskeletal Disorders pada Pegawai

\begin{tabular}{|c|c|c|c|c|c|c|}
\hline \multirow{3}{*}{ Variabel } & \multicolumn{4}{|c|}{$\begin{array}{c}\text { Keluhan Musculoskeletal } \\
\text { Disorders }\end{array}$} & \multirow{3}{*}{ p-value } & \multirow{3}{*}{ OR (CI 95\%) } \\
\hline & \multicolumn{2}{|c|}{$\begin{array}{c}\text { Keluhan } \\
\text { Tinggi }\end{array}$} & \multicolumn{2}{|c|}{$\begin{array}{l}\text { Keluhan } \\
\text { Rendah }\end{array}$} & & \\
\hline & $\mathbf{n}$ & $\%$ & n & $\%$ & & \\
\hline \multicolumn{7}{|l|}{ Usia } \\
\hline > 37 Tahun & 35 & 66,0 & 18 & 34,0 & 0,001 & $5,000(2,160-11,573)$ \\
\hline$\leq 37$ Tahun & 14 & 28,0 & 36 & 72,0 & & \\
\hline \multicolumn{7}{|l|}{ Masa Kerja } \\
\hline$>10$ Tahun & 41 & 55,4 & 33 & 44,6 & 0,020 & $3,261(1,281-8,303)$ \\
\hline$\leq 10$ Tahun & 8 & 27,6 & 21 & 72,4 & & \\
\hline \multicolumn{7}{|l|}{ Jenis Kelamin } \\
\hline Laki-laki & 23 & 45,1 & 28 & 54,9 & 0,764 & $0,821(0,379-1,782)$ \\
\hline Perempuan & 26 & 50,0 & 26 & 50,0 & & \\
\hline \multicolumn{7}{|l|}{ IMT } \\
\hline Tidak Normal & 26 & 55,3 & 21 & 44,7 & 0,213 & $1,776(0,811-3,889)$ \\
\hline Normal & 23 & 41,1 & 33 & 58,9 & & \\
\hline \multicolumn{7}{|l|}{ Aktifitas Fisik } \\
\hline Aktifitas Fisik Kurang & 22 & 47,8 & 24 & 52,2 & 1,000 & $1,019(0,468-2,217)$ \\
\hline Aktifitas Fisik Cukup & 27 & 47,4 & 30 & 52,6 & & \\
\hline
\end{tabular}

Berdasarkan tabel 4 dapat diketahui bahwa pegawai dengan usia $\leq 37$ tahun mayoritas 35 pegawai atau $(66,0 \%)$ memiliki keluhan MSDs yang tinggi. Pada tabel 4 dapat diketahui bahwa mayoritas pegawai di Biro Kepegawaian dengan masa kerja $>10$ tahun sebanyak 41 pegawai atau $(55,4 \%)$ mempunyai keluhan MSDs tinggi. Sebanyak 26 pegawai atau $(50,0 \%)$ berjenis kelamin perempuan mengalami keluhan musculoskeletal tinggi, sedangkan keluhan musculoskeletal rendah dirasakan oleh laki-laki dengan sebanyak 28 pegawai atau $(54,9 \%)$. Pada tabel 4 dapat diketahui bahwa mayoritas pegawai di Biro Kepegawaian dengan kategori IMT tidak normal mengalami keluhan MSDs tinggi sebanyak 26 pegawai atau (55,3\%). Mayoritas pegawai di Biro Kepegawaian dengan kategori aktifitas fisik cukup sebanyak 30 pegawai atau $(52,6 \%)$ mempunyai keluhan rendah MSDs. Pada tabel 4 dapat diketahui bahwa mayoritas pegawai di Biro Kepegawaian dengan kategori aktifitas fisik cukup sebanyak 30 pegawai atau $(52,6 \%)$ mempunyai keluhan rendah MSDs.

Berdasarkan uji chi-square jika nilai $p$ value $>0,05$ artinya terdapat hubungan yang signifikan antara 2 variabel. Berdasarkan tabel 4 variabel yang berhubungan dengan keluhan musculoskeletal disorders adalah usia dan masa kerja.

Tabel 5. Analisis Bivariat antara Faktor Pekerjaan dengan Keluhan Musculoskeletal Disorders pada Pegawai

\begin{tabular}{|c|c|c|c|c|c|c|}
\hline \multirow{3}{*}{ Variabel } & \multicolumn{4}{|c|}{ Keluhan Musculoskeletal Disorders } & \multirow{3}{*}{ p-value } & \multirow{3}{*}{ OR (CI 95\%) } \\
\hline & \multicolumn{2}{|c|}{ Keluhan Tinggi } & \multicolumn{2}{|c|}{ Keluhan Rendah } & & \\
\hline & $\mathbf{n}$ & $\%$ & n & $\%$ & & \\
\hline \multicolumn{7}{|l|}{ Postur Kerja } \\
\hline Berisiko & 29 & 40,3 & 43 & 59,7 & 0,041 & $0,371(0,155-0,889)$ \\
\hline Tidak Berisiko & 20 & 64,5 & 11 & 35,5 & & \\
\hline \multicolumn{7}{|l|}{ Durasi Kerja } \\
\hline$>8 \mathrm{Jam}$ & 27 & 43,5 & 35 & 56,5 & 0,421 & $0,666(0,301-11,472)$ \\
\hline$\leq 8 \mathrm{Jam}$ & 22 & 53,7 & 19 & 46,3 & & \\
\hline
\end{tabular}

Berdasarkan tabel 5 diketahui bahwa mayoritas dari 43 pegawai di Biro Kepegawaian atau $(59,7 \%)$ dengan postur kerja bersiko mengalami keluhan tinggi MSDs. Pada tabel 5 dapat diketahui bahwa mayoritas pegawai di Biro Kepegawaian dengan durasi kerja $>8$ jam sebanyak 35 pegawai atau $(56,5 \%)$ mempunyai keluhan tinggi MSDs.
Hasil uji statistik didapatkan nilai $p$ value $=0,041$ untuk variabel postur kerja, artinya adanya korelasi antara postur kerja dengan keluhan MSDs. Nilai $p$-value untuk variabel durasi kerja sebesar 0,421 yang artinya tidak terdapat keterkaitan antara durasi kerja dengan keluhan MSDs. 


\section{PEMBAHASAN}

\section{Hubungan Usia dengan Keluhan Musculoskeletal Disorders}

Pada penelitian ini diketahui bahwa kategori usia didominasi oleh usia dimiliki oleh responden $>37$ tahun dengan 35 pegawai atau $(66,0 \%)$ mempunyai keluhan MSDs yang tinggi. Berdasarkan hasil uji statistik diketahui usia berhubungan dengan keluhan MSDs pada pegawai di Biro Kepegawaian Kemenkes RI ( $p$ value 0,001 ).

Hasil penelitian uji chi-square yang dilakukan oleh Tambuwun, dkk sejalan, diketahui bahwa hasil uji chi-square dengan nilai $p$ value $=0,002 \quad(\alpha=0,05)$ menunjukkan terdapat hubungan bermakna antara usia dengan keluhan musculoskeletal pada pekerja di Desa Leilem Dua Kecamatan Sonder Tambuwun, dkk, (2020).

Menurut penelitian yang dilakukan Shobur, dkk, (2019) salah satu yang mempengaruhi kerja otot adalah umur, karena semakin bertambahnya umur seseorang dalam kondisi ini berkurangnya kekuatan otot, hal ini menunjukkan bahwa terdapat hubungan antara umur dengan keluhan muskuloskeletal dengan perkerja berusia $\geq 30$ tahun karena berisiko 4,4 kali mengalami keluhan musculoskeletal tingkat tinggi dibandingkan dengan perkerja dengan usia $<30$ tahun.

\section{Hubungan Masa Kerja dengan Keluhan Musculoskeletal Disorders}

Pada penelitian yang dilakukan dengan 103 responden dapat diketahui bahwa terdapat 41 pegawai atau $(55,4 \%)$ dengan keluhan MSDs, dapat disimpulkan bahwa ada hubungan antara masa kerja dengan keluhan MSDs pada pegawai di Biro Kepegawaian RI dengan hasil uji analisis p-value 0,020 .

Penelitian yang dilakukan oleh (Sari dan Rifai, 2019) didapatkan hasil uji chi-square dengan nilai signifikan 0,000 ( $p$-value< 0,05$)$. Maka dapat disimpulkan bahwa terdapat hubungan antara masa kerja dengan keluhan MSDs pada pembatik Giriloyo Kabupaten Bantul.

Berdasarkan hasil penelitian yang dilakukan oleh (Sulistiyo dan Sitorus, 2018) didapatkan nilai $p$-value $0,002<0,05$ yang dapat disimpukan bahwa ada hubungan antara masa kerja dengan keluhan MSDs pada radiographer, hal ini terjadi karena semakin lama pekerja melakukan pekerjaan yang sama dan dilakukan secara berulang maka risiko terjadi keluhan
MSDs akan terjadi karena masa kerja adalah faktor risiko yang dapat mempengaruhi individu akan terjadinya risiko keluhan musculoskeletal. Jika pekerja mengalami posisi janggal dalam waktu yang lama akan terjadinya peningkatan risiko karena otot mendapatkan beban yang statis secara repetitive dan waktu yang cukup lama, sehingga dapat mengakibatkan terjadinya keluhan seperti kerusakan pada sendi, ligamen, dan otot.

\section{Hubungan Postur Kerja dengan Keluhan Musculoskeletal Disorders}

Postur kerja merupakan posisi tubuh yang dilakukan dalam kegiatan saat bekerja. Postur kerja yang kurang baik dapat mengakibatkan risiko terjadinya keluhan muskuloskeletal (Tarwaka, 2015). Berdasarkan hasil uji statistik didapatkan bahwa p-value 0,041 , sehingga dapat disimpulkan adanya hubungan antara postur kerja dengan keluhan musculoskeletal disorders pada pegawai di Biro Kepegawaian Kementerian Kesehatan RI.

Penelitian ini sejalan dengan penelitian oleh (Djaali dan Utami, 2019) berdasarkan hasil uji statistic dengan uji chi-square didapatkan bahwa terdapat hubungan antara postur kerja dengan keluhan musculoskeletal disorders pada karyawan PT. Control System Arena Para Nusa dengan nilai $p$-value 0,008 .

Pada hasil penilaian yang dilakukan peneliti dengan menggunakan metode ROSA, pada kegiatan kerja duduk diketahui kursi yang digunakan oleh setiap pegawai tidak sesuai dengan kondisi antropometri yang dimiliki. Desain kursi yang digunakan dengan sandaran lengan yang keras, lebar dan tinggi sandaran punggung tidak sesuai dengan badan responden. Desain sandaran kursi yang digunakan seharusnya dapat disesuaikan dengan pinggang dan tinggi kursi tidak disesuaikan dengan tinggi badan per individu untuk mencegah terjadinya keluhan otot pada bagian punggung bawah dan bagian leher (Permenkes RI, 2016).

\section{Hubungan Jenis Kelamin dengan Keluhan Musculoskeletal Disorders}

Pada penelitian ini mayoritas pegawai memiliki jenis kelamin perempuan. Berdasarkan hasil penelitian yang dilakukan diketahui bahwa dari 26 pegawai atau $(50,0 \%)$ berjenis kelamin perempuan mengalami keluhan musculoskeletal tinggi dan rendah, dengan hasil analisis bahwa $p$ value 0,764 , maka tidak ada hubungan antara 
jenis kelamin dengan keluhan MSDs pada pegawai di Biro Kepegawaian Kemenkes RI.

Penelitian ini sesuai dengan penelitian yang dilakukan oleh Balaputra dan Sutomo, (2017) yang menyatakan bahwa perempuan dan laki-laki mempunyai risiko yang sama untuk terjadinya gangguan musculoskeletal hingga usia 60 tahun, perempuan lebih sering mendapati gangguan tersebut pada saat siklus menstruasi dan proses terjadinya menopause yang mengakibatkan kepadatan pada tulang berkurang, maka tidak adanya hubungan jenis kelamin dengan keluhan gangguan musculoskeletal.

Namun hal ini tidak sejalan dengan penelitian yang dilakukan oleh Widianingtyas, (2019) dengan nilai $p$-value didapatkan 0,05 ( $p$ value $<0,05)$, karena jenis kelamin perempuan memiliki kekuatan otot yang berkisar $2 / 3$ dari kekuatan otot pria berpengaruh terhadap faktor fisologis kekuatan otot.

\section{Hubungan Indeks Masa Tubuh (IMT) dengan Keluhan Musculoskeletal Disorders}

Pada penelitian ini, mayoritas pegawai di Biro Kepegawaian dengan kategori IMT tidak normal mengalami keluhan MSDs tinggi sebanyak 26 pegawai atau $(55,3 \%)$. Hasil uji statistik didapatkan bahwa p-value 0,066 , maka dapat disimpulkan yang menunjukkan tidak ada hubungan yang signifikan antara IMT dengan keluhan MSDs pada pegawai di Biro Kepegawaian Kementerian Kesehatan RI.

Penelitian ini bertentangan dengan penelitian yang dilakukan oleh Icsal dkk, (2016) menyatakan bahwa terdapat hubungan antara indeks masa tubuh (IMT) dengan keluhan MSDs pada penjahit wilayah pasar panjang kota Kendari. Mayoritas penjahit di wilayah pasar panjang kota Kendari dengan IMT gemuk dan obesitas, hal ini dapat dikaitkan dengan semakin gemuk seseorang maka menyebabkan ketidaksanggupan tubuh dalam menopang beban tubuh yang dapat membuat tubuh merasakan nyeri.

\section{Hubungan Aktifitas Fisik dengan Keluhan Musculoskeletal Disorders}

Aktivitas fisik ialah gerakan tubuh yang dihasilkan oleh otot rangka yang membutuhkan pengeluaran pengeluaran energi. Pada penelitian ini hasil analisis dapat diketahui bahwa $p$-value 1,000 yang dapat disimpulkan tidak adanya hubungan antara aktifitas fisik dengan keluhan musculoskeletal disorders pada pegawai di Biro Kepegawaian Kementerian Kesehatan RI.
Berdasarkan hasil analisis yang dilakukan oleh (Jusman, 2018) dengan nilai statistik $p$-value $(1,000)>0,05$ yang artinya tidak terdapat hubungan yang signifikan antara aktifitas fisik dengan keluhan MSDs, responden yang mempunyai aktifitas berat berkesempatan mengalami MSDs dibandingan dengan responden yang memiliki aktifitas ringan (Jusman, 2018). Aktivitas fisik berhubungan dengan kegiatan sehari-hari yang dilakukan oleh individu. Biasanya, MSDs terjadi bagi mereka yang melakukan kegiatan dengan tenaga yang besar dan waktu untuk istirahat yang kurang. Sehingga keluhan otot meningkat sejalan dengan bertambahnya aktivitas fisik (Bridger dalam Jusman, 2018).

\section{Hubungan Durasi Kerja dengan Keluhan Musculoskeletal Disorders}

Pada penelitian ini diketahui bahwa mayoritas pegawai di Biro Kepegawaian dengan durasi kerja $>8$ jam sebanyak 35 pegawai atau $(56,5 \%)$ mempunyai keluhan rendah musculoskeletal disorders. Didapatkan hasil $p$ value $0,421, p$-value $\geq 0,05$ yang menunjukkan tidak ada keterkaitan antara durasi kerja dengan keluhan MSDspada pegawai di Biro Kepegawaian Kementerian Kesehatan RI.

Penelitian ini tidak sejalan dengan penelitian yang dilakukan oleh Male, dkk, (2018) dihasilkan uji statistik yang didapatkan nilai $p$ value 0,03 , terdapat hubungan antara durasi kerja dengan keluhan musculoskeletal pada pekerja lapangan di proyek jalan tol Manado-Bitung. Dalam penelitian yang dilakukan oleh Meilani dkk, (2018) menyatakkan dapat disimpulkan bahwa adanya hubungan antara durasi kerja dengan keluhan musculoskeletal disorders pada pekerja operator sewing di PT Dasan Pan Fasific Indonesia tahun 2018.

Hasil penelitian yang dilakukan oleh Utami dan Jufri, (2017) sebagian besar responden bekerja dalam durasi kerja >8 jam/hari dan istirahat yang kurang mencukupi, sehingga peningkatan beban kerja otot sekeletal persendian akan meningkat karena seimbangnya waktu kerja dengan istirahat.

\section{SIMPULAN}

Faktor indvidu baik variabel usia maupun variabel masa kerja, serta faktor pekerjaan yaitu variabel postur kerja memiliki hubungan antara keluhan musculoskeletal disorders pada pegawai di Biro Kepegawaian Kementerian Kesehatan 
Republik Indonesia. Namun tidak memiliki hubungan antara jenis kelamin, aktivitas fisik, dan durasi kerja dengan keluhan musculoskeletal disorders pada pegawai di Biro Kepegawaian Kementerian Kesehatan Republik Indonesia.

\section{DAFTAR PUSTAKA}

Aziz, B. A., Handoko, L., \& Juniani, A. I. (2018). Analisis Risiko Keluhan Musculoskeletal dengan Metode RULA di Perusahaan Bidang Kimia. [Skrispi]. Surabaya: Program Studi D4 Teknik Keselamatan dan Kesehatan Kerja-PPNS (pp. 467-474). Politeknik Perkapalan Negeri Surabaya.

Badan Penelitian dan Pengembangan Kesehatan. (2013). Riset Kesehatan Dasar (RISKESDAS) 2013. Laporan Nasional 2013. https://doi.org/1 Desember 2013

Balaputra, I., \& Sutomo, A. H. (2017). Pengetahuan ergonomi dan postur kerja perawat pada perawatan luka dengan gangguan. Berita Kedokteran masyarakat, 33(9), 445-448.

Dewi, A. M. P. (2019). Hubungan Antara postur Kerja dengan Keluhan Musculoskeletal Disorders pada Pegawai Administrasi di Kantor Pusat Universitas Jember. [Skripsi]. Jember: Fakultas Kedokteran, Universitas Jember.

Djaali, N. A., \& Utami, M. P. (2019). ANALISIS KELUHAN MUSCULOSKELETAL DISORDERS (MSDs) PADA KARYAWAN PT. CONTROL SYSTEM ARENA PARA NUSA. Jurnal Ilmiah Kesehatan, 11(1), 80-87.

Icsal, M., Sabilu, Y., \& Pratiwi, A. D. (2016). Faktor yang berhubungan dengan keluhan musculoskeletal disorders (msds) pada penjahit wilayah pasar panjang kota kendari tahun 2016. Jurnal Ilmiah Mahasiswa Kesehatan Masyarakat, 1(2).

Jusman, N. (2018). Faktor-Faktor Risiko Ergonomi Dengan Keluhan Subjektif Musculoskeletal Disorders (Msds) Pada Operator Cutting Bar Di Unit Produksi PT Iron Wire Works Indonesia Tahun 2018. [Skripsi]. Jakarta: Fakultas Ilmu Kesehatan, Universitas Esa Unggul.

Krisdianto, Dewi, A., \& Ismi, R. (2015). Hubungan Faktor Individu dan Faktor Pekerjaan dengan Keluhan Muskuloskeletal Akibat Kerja (Studi Pada Nelayan di Desa Puger Wetan Kecamatan Puger Kabupaten Jember) The Relationship Between
Bagi pekerja harus menambah aktivitas fisik di luar jam kerja sebanyak 3 kali dengan durasi 30 menit, perlu menata ulang kembali desain tempat kerja, pekerja melakukan istirahat guna peregangan otot selama 10-15 menit setiap satu jam sekali.

Individual Factor and Work Factor With Work district Puger Distr. Artikel Ilmiah Hasil Penelitian Mahasiswa, Jember: Universitas Jember. 2-7.

Luan, H. D., Hai, N. T., Xanh, P. T., Giang, H. T., Van Thuc, P., Hong, N. M., \& Khue, P. M. (2018). Musculoskeletal Disorders: Prevalence and Associated Factors among District Hospital Nurses in Haiphong, Vietnam. BioMed Research International, 2018. https://doi.org/10.1155/2018/3162564

Mahmud, N., Kenny, D. T., Zein, R. M., \& Hassan, S. N. (2011). Ergonomic Training Reduces Musculoskeletal Disorders among Office Workers: Results from the 6-Month FollowUp. Malaysian J Med Sci, 2(18), 16-26. https://www.ncbi.nlm.nih.gov/pmc/articles /PMC3216214/pdf/mjms-18-2-016.pdf

Male, I. Y., Kandou, G. D., \& Suoth, L. F. (2018). Hubungan Antara Lama Kerja Dan Sikap Kerja Dengan Keluhan Muskuloskeletal Pada Pekerja Lapangan Di Proyek Jalan Tol Manado-Bitung Tahun 2018. Jurnal KESMAS, 7(5), 1-7.

Meilani, F., Asnifatima, A., \& Fathimah, A. (2018). Faktor-faktor Risiko Yang Mempengaruhi Keluhan MUSCULOSKELETAL DISORDER (MSDs) Pada pekerja Operator Sewing DI PT DASAN PAN FASIFIC INDONESIA Tahun 2018. Promotor Jurnal Mahasiswa Kesehatan Masyarakat, 1(1), 1-6.

Permenkes RI. (2016). PMK No 48 Standar Keselamatan dan Kesehatan Kerja Perkantoran. Kementerian Kesehatan RI.

Piranveyseh, P., Motamedzade, M., Osatuke, K., Mohammadfam, I., Moghimbeigi, A., Soltanzadeh, A., \& Mohammadi, H. (2016). Association between Psychosocial, Organizational and Personal Factors and Prevalence of Musculoskeletal Disorders in Office Workers. International Journal of Occupational Safety and Ergonomics, 22(2), 267-273.

https://doi.org/10.1080/10803548.2015.1135568 Sari, R. O., \& Rifai, M. (2019). Hubungan Postur 
Kerja dan Masa Kerja dengan Keluhan Muculoskeletal Disorders (MSDs) pada Pembatik Giriloyo di Kabupaten Bantul. Naskah Publikasi. Yogyakarta: Universitas Ahmad Dahlan.1-15.

Sekaaram, V., \& Ani, L. S. (2017). Prevalensi Musculoskeletal Disorders (MSDs) pada Pengemudi Angkutan Umum di Terminal Mengwi, Kabupaten Badung-Bali. Intisari Sains Medis, 8(2), 118-124. https://doi.org/10.1556/ism.v8i2.125

Shobur, S., Maksuk, M., \& Sari, F. I. (2019). Faktor Risiko Musculoskeletal Disorders (MSDs) pada Pekerja Tenun Ikat di Kelurahan Tuan Kentang Kota Palembang. Jurnal Medikes (Media Informasi Kesehatan), 6(2), 113-122.

Sulistiyo, T. H., \& Sitorus, R. J. (2018). Analisis faktor risiko ergonomi dan musculoskeletal disorders pada radiografer instalasi radiologi rumah sakit di kota palembang Abstr a ct sakit di Kota Palembang Provinsi Sumatera radiografer observasi lapangan serta wawancara dengan kesimpulan mengguna. Jurnal Kesehatan Dan Kedokteran, 5(1), 26-37.

Tambuwun, J. H., Malonda, N. S. H., \& Kawatu, P. A. T. (2020). Hubungan Antara Usia dan Masa Kerja dengan Keluhan Muskulo- skeletal pada Pekerja Mebel di Desa Leilem Dua Kecamatan Sonder. Medical Scope Journal, 1(2), 1-6. https://doi.org/10.35790/msj.1.2.2020.27201

Tarwaka. (2015). Ergonomi Industri DasarDasar Pengetahuan Ergonomi Dan Aplikasi di Tempat Kerja. Surakarta: Harapan Press.

Utami, U., Karimuna, S. R., \& Jufri, N. N. (2017). Hubungan Lama Kerja, Sikap Kerja dan Beban Kerja dengan Muskuloskeletal Disorders (MSDs) pada Petani Padi di Desa Ahuhu Kecamatan Meluhu Kabupaten Konawe Tahun 2017. Jurnal Ilmiah Mahasiswa Kesehatan Masyarakat, 2(6).

Valipour Noroozi, M., Hajibabaei, M., Saki, A., \& Memari, Z. (2015). Prevalence of Musculoskeletal Disorders Among Office Workers. Jundishapur Journal of Health Sciences, $\quad 7(1), \quad 1-5$. https://doi.org/10.5812/jjhs.27157

WHO. (2013). Protecting Workers Health. World Health Organization.

Widianingtyas, N. Y. (2019). Identifikasi Faktor Penyebab Muculoskeletal Disorders pada Siswa SMP di Kecamatan Pracimantoro Wonogiri. 